University of Nebraska - Lincoln DigitalCommons@University of Nebraska - Lincoln

2012

\title{
Elevated temperature characterization of electron beam freeform fabricated Ti-6Al-4V and dispersion strengthened $\mathrm{Ti}-8 \mathrm{Al}-1 \mathrm{Er}$
}

RW. Bush

U.S. Air Force Academy

C A. Brice

Lockheed Martin Aeronautics Co.

Follow this and additional works at: http:// digitalcommons.unl.edu/usafresearch

Bush, R W. and Brice, C A., "Elevated temperature characterization of electron beam freeform fabricated Ti-6Al-4V and dispersion strengthened Ti-8Al-1Er" (2012). U.S. Air Force Research. 45.

http://digitalcommons.unl.edu/usafresearch/45

This Article is brought to you for free and open access by the U.S. Department of Defense at DigitalCommons@University of Nebraska - Lincoln. It has been accepted for inclusion in U.S. Air Force Research by an authorized administrator of DigitalCommons@University of Nebraska - Lincoln. 


\title{
Elevated temperature characterization of electron beam freeform fabricated $\mathrm{Ti}-6 \mathrm{Al}-4 \mathrm{~V}$ and dispersion strengthened $\mathrm{Ti}-8 \mathrm{Al}-1 \mathrm{Er}$
}

\author{
R.W. Bush ${ }^{a}, *$ C.A. Brice ${ }^{b}$ \\ a Department of Engineering Mechanics, 2354 Fairchild Dr., U.S. Air Force Academy, USAF Academy, CO 80840, United States \\ ${ }^{\mathrm{b}}$ Lockheed Martin Aeronautics Co., Fort Worth, TX, United States
}

\section{A R T I C L E I N F O}

\section{Article history:}

Received 24 May 2012

Accepted 26 May 2012

Available online 21 June 2012

\section{Keywords:}

Titanium alloys

Electron beam freeform fabrication

Elevated temperature tensile strength

Creep

Dispersion strengthening

\begin{abstract}
A B S T R A C T
Electron beam freeform fabrication is an additive manufacturing process that can be used to build fully dense, structural metallic parts directly from a three-dimensional computer model. This technique can replace conventional fabrication methods, such as forging or machining from plate, and enable significant cost, time, and tool savings. Additionally, this method enables the fabrication of alloys with novel compositions that are not well suited to production via ingot metallurgy processes. Ti-8Al-1Er is an experimental dispersion strengthened titanium alloy composition that requires rapid cooling to achieve optimal properties and thus is not amenable to ingot metallurgy production methods. Oxide dispersion strengthened alloys, such as Ti-8Al-1Er are known to have excellent thermal stability and improved high temperature properties.

In this work, the room temperature tensile, elevated temperature tensile, creep properties and oxidation resistance of electron beam additive manufactured $\mathrm{Ti}-6 \mathrm{Al}-4 \mathrm{~V}$ and $\mathrm{Ti}-8 \mathrm{Al}-1 \mathrm{Er}$ were measured and compared to those of laser beam additive manufactured $\mathrm{Ti}-8 \mathrm{Al}-1 \mathrm{Er}$ and wrought Ti-6Al-4V. Elevated temperature tensile properties were measured between $93^{\circ}$ and $538^{\circ} \mathrm{C}$. Creep tests were performed between $425^{\circ}$ and $455^{\circ} \mathrm{C}$ at stresses between 345 and $483 \mathrm{MPa}$. It was found that the elevated temperature properties of the electron beam additive manufactured products are comparable to those of wrought forms. The elevated temperature strengths of Ti-8Al-1Er are comparable to those of Ti-6Al-4V in percentage of room temperature strength retained at temperature. Based on a Larson-Miller analysis of the creep test data, the creep resistance of Ti-8Al-1Er is superior to that of Ti-6Al-4V, but inferior to that of laser beam additive manufactured $\mathrm{Ti}-8 \mathrm{Al}-1 \mathrm{Er}$. The inter-alloy improvement in creep resistance increases with decreasing temperature and stress. The oxidation resistance of Ti-8Al-1Er is superior to that of $\mathrm{Ti}-6 \mathrm{Al}-4 \mathrm{~V}$.
\end{abstract}

Published by Elsevier B.V.

\section{Introduction}

Electron beam additive manufacturing is a process that has been developed for fabricating near-net shaped metallic parts [1-5]. This process uses a three-dimensional computer model to drive a motion control system that additively deposits material in a stepwise, layered manner. A metal wire feedstock is fed into a molten pool formed by an electron beam heat source creating a bead of deposited material. Additional beads are deposited incrementally until the entire 3D shape has been created. The end product is a near-net shape part that can, with proper processing parameters, be fully dense and have mechanical properties similar or equivalent to wrought or forged material [6-10]. If successfully utilized, this process could decrease manufacturing costs through

\footnotetext{
* Corresponding author. Tel.: +1 7193337940

E-mail address: ralph.bush@usafa.edu (R.W.Bush).
}

reduction of part count, elimination of machining steps, and reduced raw material requirements.

In addition, electron beam additive manufacturing may enable the production of unique alloys via in situ alloying enabled by the rapid solidification inherent to the process. Oxide dispersion strengthened alloys, which benefit from rapid solidification are well suited for additive manufacturing processes. A number of these materials have been studied to evaluate the possibility of increasing the operating temperature range of titanium alloys. These studies found that elevated temperature tensile properties and creep performance of the dispersion strengthened titanium alloys were superior to those of conventional alloys $[11,12]$. In these alloys, the requirements for effective dispersoids are: (a) stable at elevated temperature, (b) incoherent with the matrix, (c) closely spaced, (d) small $(0.05-0.5 \mu \mathrm{m})$, and (e) homogeneously distributed $[11,13,14]$. While additions of rare-earth elements such as erbium to titanium alloys have been shown to develop the required dispersion characteristics in rapidly solidified alloys, attempts at incorporating these elements into slowly cooled conventional 
ingots have been unsuccessful, resulting in coarse particles with poor dispersions $[11,12,14]$. The increased solidification rates associated with laser-beam deposited titanium alloys has been shown to develop rare-earth dispersions that meet the necessary requirements for improved elevated temperature performance [15-17].

In this work, a titanium alloy with a nominal composition of $8 \%$ aluminum, $1 \%$ erbium (Ti-8Al-1Er) was studied. The alloy was deposited using an electron beam additive manufacturing process and the resulting material was characterized using a series of elevated temperature test methods. The properties were compared to those of laser-beam deposited $\mathrm{Ti}-8 \mathrm{Al}-1 \mathrm{Er}$ characterized in a previous study [16]. For comparison, specimen blanks of Ti-6Al-4V were also prepared from electron beam deposited material and characterized using the same test methods. The results from this testing were compared to those of wrought Ti-6Al-4V. This work allows the comparison of material properties of conventional wrought versus electron beam additive manufactured material.

The primary goal of this study was to determine how effectively an electron beam deposition process could produce a product with the fine dispersoids necessary for high temperature performance. This study also aimed to compare the property improvements noted in previous work on rapidly solidified rare-earth containing titanium alloys to the properties of a product made by electron beam deposition. Since the electron beam deposition process fabricates net or near-net shape parts, no thermomechanical post-processing is required, thus avoiding any detrimental microstructure changes. A secondary goal is to compare properties of the electron beam additive manufactured $\mathrm{Ti}-8 \mathrm{Al}-1 \mathrm{Er}$ to those of widely used commercial alloys.

\section{Experimental}

\subsection{Material}

The alloys used in this work were $\mathrm{Ti}-8 \mathrm{Al}-1 \mathrm{Er}$, an experimental dispersion strengthened alpha titanium alloy, and Ti-6Al-4V. The Ti-8Al-1Er composition was chosen in order to demonstrate sufficiently rapid solidification using the electron beam additive manufacturing process such that a fine, homogeneous dispersion of oxide particles could be achieved. In Ti-8Al-1Er the aluminum contributes to solid solution strengthening and $\alpha$ phase stabilization while erbium reacts with residual oxygen during solidification to form $\mathrm{Er}_{2} \mathrm{O}_{3}$ dispersoids. These dispersoids are useful for grain size control and elevated temperature strength and creep improvement. The increase in beta transus temperature as a result of the aluminum addition provides high temperature phase stability due to the much slower coarsening kinetics provided by the hcp alpha phase. Ti-6Al- $4 \mathrm{~V}$ is a standard $\alpha-\beta$ alloy in which both aluminum and vanadium are used for solid solution strengthening.

Electron beam deposited $\mathrm{Ti}-8 \mathrm{Al}-1 \mathrm{Er}$ and $\mathrm{Ti}-6 \mathrm{Al}-4 \mathrm{~V}$ materials were supplied for this study by Lockheed-Martin. Cylindrical deposits were made using a Sciaky electron beam additive manufacturing system from which test specimens were extracted along the build direction, parallel to the $z$-axis (Fig. 1). The original deposits were approximately $150 \mathrm{~mm}$ in diameter with a wall thickness of $25 \mathrm{~mm}$ and a finished height of $200 \mathrm{~mm}$. Each layer was created using an outward spiral pattern such that eight full revolutions around the $z$-axis were completed with each concentric spiral overlapping the previous by approximately $33 \%$. Upon completion of each layer, the $z$-axis was incremented up $1 \mathrm{~mm}$ and indexed back to the starting position. This process was repeated until 200 layers were deposited for a total build height of $200 \mathrm{~mm}$. From these deposits, cylindrical test blanks with a diameter of $16 \mathrm{~mm}$ and length of $160 \mathrm{~mm}$ were extracted with the text axis parallel to the $z$ orientation in the deposit (see Fig. 1). The Ti-8Al-1Er blanks

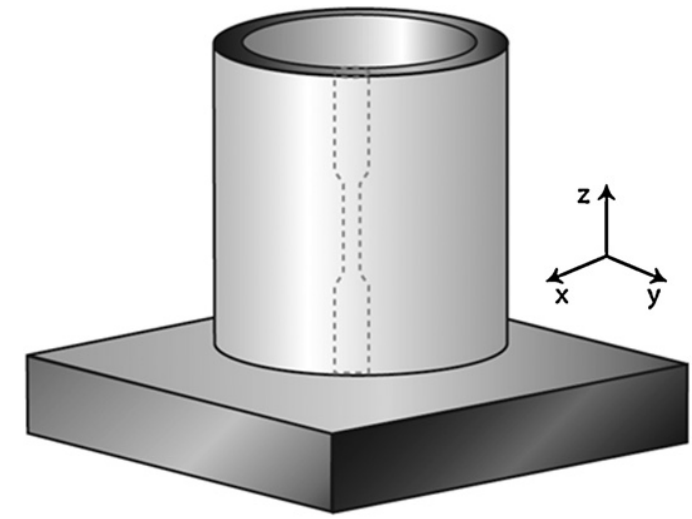

Fig. 1. Material deposition and specimen extraction schematic

were annealed at $700^{\circ} \mathrm{C}$ for $2 \mathrm{~h}$ to provide stress relief and aid in secondary precipitation of $\mathrm{Er}_{2} \mathrm{O}_{3}$ dispersoids, then subsequently air cooled. The Ti-6Al-4V blanks were given a heat treatment similar to a $\beta$ anneal, specifically $1010^{\circ} \mathrm{C}$ ( $\beta$ phase field) for $35 \mathrm{~min}$, air cooled to room temperature, then $730^{\circ} \mathrm{C}$ for $2 \mathrm{~h}$ and then air cooled. The bars were machined into cylindrical dogbone test specimens with threaded ends and $6.3 \mathrm{~mm}$ diameter test sections.

A columnar grain structure with the long axis of the grains parallel to the $z$-axis build direction is often observed in electron deposited parts. Fig. 2 shows this columnar structure in the as-received $\mathrm{Ti}-6 \mathrm{Al}-4 \mathrm{~V}$ part. In contrast, the $\mathrm{Ti}-8 \mathrm{Al}-1 \mathrm{Er}$ part microstructure, shown in Fig. 3, showed no evidence of columnar grain structure, but rather a more equiaxed grain structure, consisting of $\alpha$ phase, with small amounts of lamellar $\alpha$ phase present. The grain size appears bi-modal in nature, with a mixture of large and small grains. The lack of a columnar grain structure indicates that the dispersoid particles are effective at disrupting the grain structure evolution typically seen in additive manufactured titanium alloys. While this microstructural change could have a positive effect on static strength, it is likely to have a negative effect on creep strength as elongated, columnar grains (parallel to the loading direction) are preferred for creep resistant applications. A higher magnification photograph of the Ti-6Al-4V microstructure in Fig. 4 shows an acicular transformed beta morphology that is typical of rapid cooling from the beta phase field. The corresponding higher magnification micrograph of Ti-8Al-1Er in Fig. 5 shows a mixture of equiaxed grains with lamellar $\alpha$ plates on the order of 10-20 $\mu \mathrm{m}$ thick emanating from grain boundaries.

Photographs taken in the SEM show the $\mathrm{Er}_{2} \mathrm{O}_{3}$ dispersoids in the Ti-8Al-1Er alloy in Fig. 6. The dispersoid radii are well within the size range required for elevated temperature alloys. The dispersoids are observed along grain boundaries and in parallel strings indicative of formation along crystallographic planes. Previous characterization work showed that these dispersoids primarily nucleate on basal planes $[15,17,18]$.

Chemical composition of each alloy is shown in Table 1 . In both alloys the aluminum content is $10-16 \%$ less than that of the feedstock wire. A similar deficit in erbium content is noted. This is consistent with the loss of aluminum content due to vaporization that occurs during the electron beam additive manufacturing process that has been documented in other aluminum-bearing titanium alloys [19]. Composition values of interstitial elements, O, $\mathrm{N}, \mathrm{C}$, and $\mathrm{H}$, were made only for the Ti-8Al-1Er wire feedstock and the subsequent electron deposited part. Chemical composition of the Ti-8Al-1Er feed wire showed that the interstitial contents of the wire and test specimens were the same, indicating that there was no contamination of the metal during electron beam deposition. Interstitial composition measurements were not made on electron 


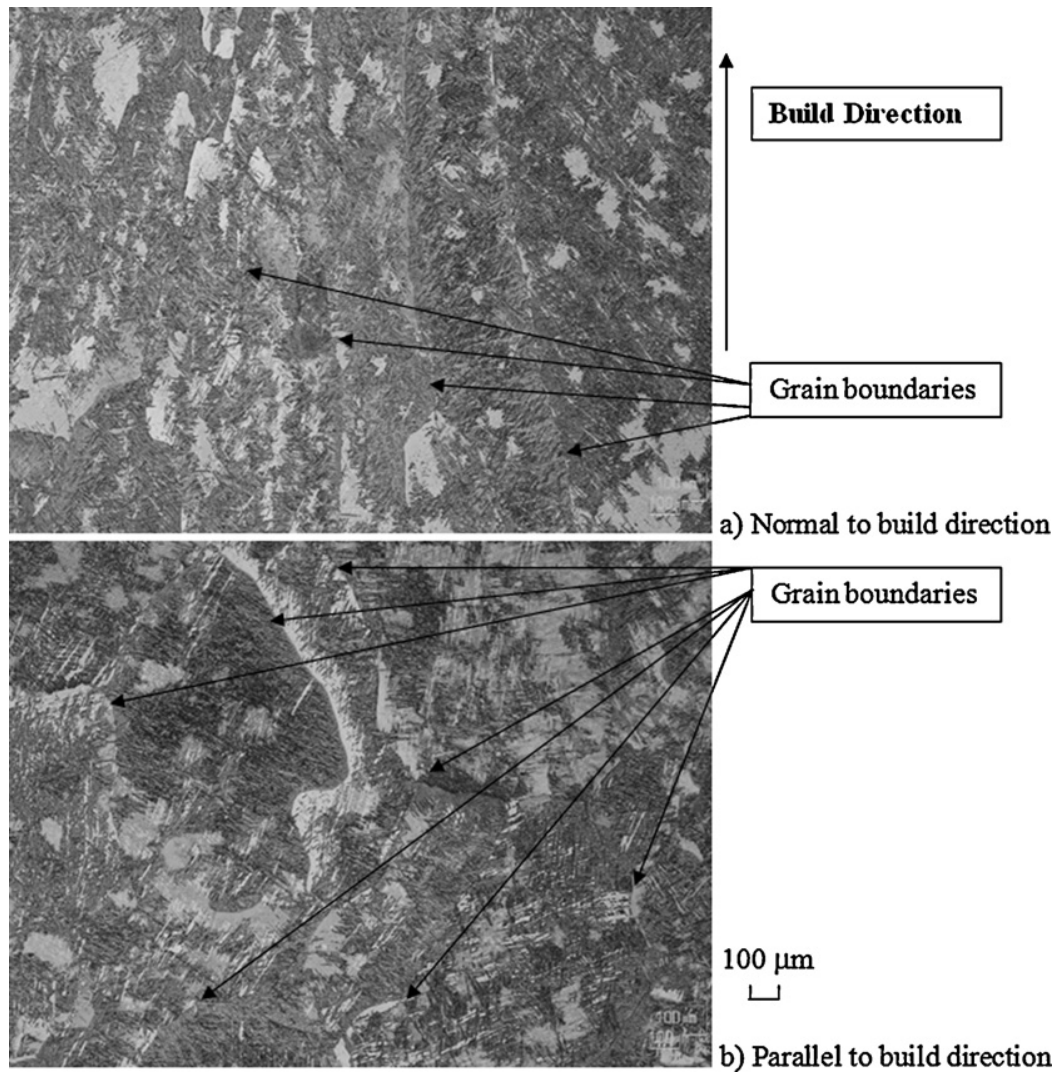

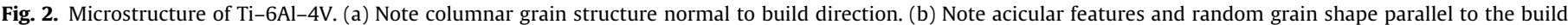
direction.

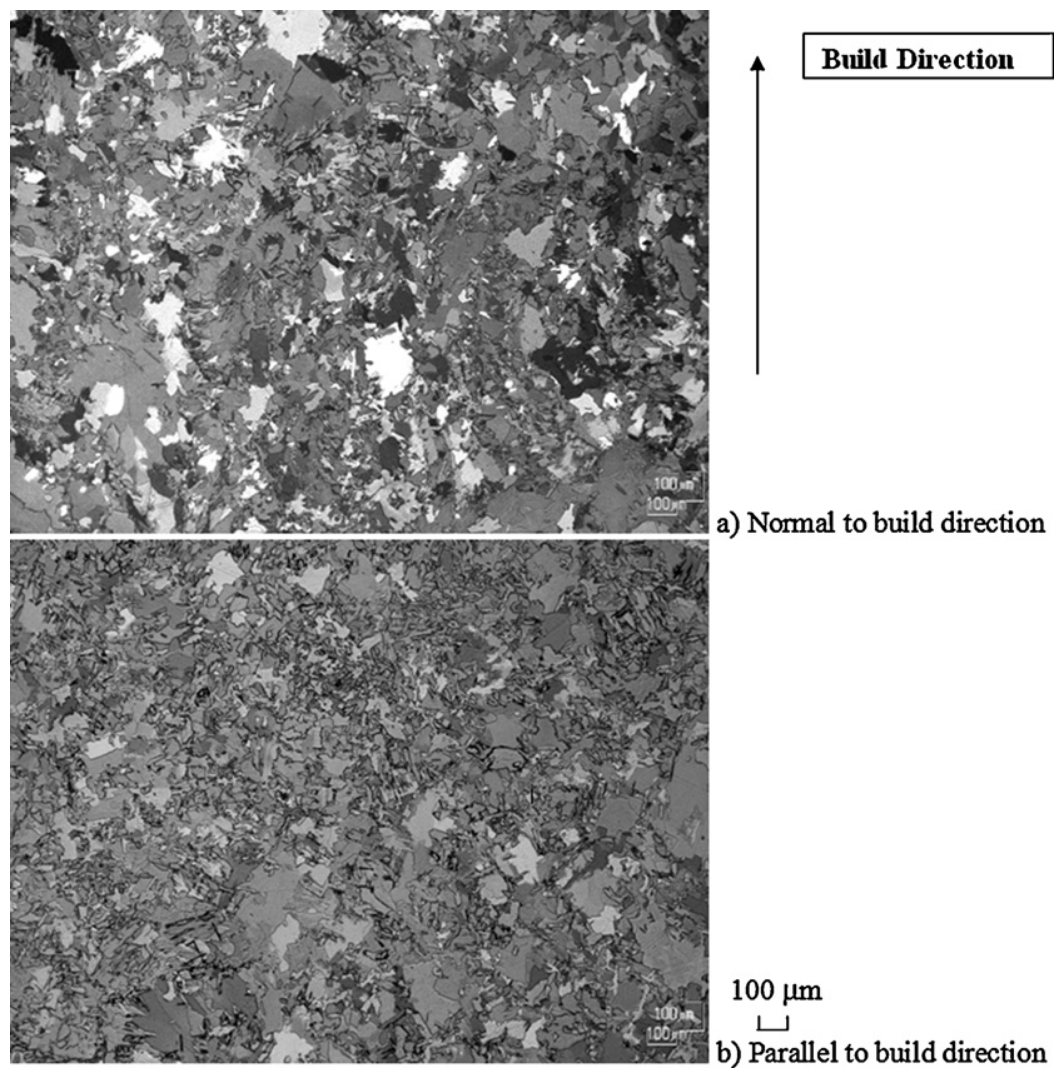

Fig. 3. Microstructure of electron beam deposited Ti-8Al-1Er showing equiaxed annealed grain structure. Note mixture of non-uniform sized large and small grains. 
Table 1

Material chemical compositions.

\begin{tabular}{|c|c|c|c|c|c|c|c|}
\hline Alloy & wt\% Al & $\mathrm{wt} \% \mathrm{~V}$ & wt\% Er & wt $\%$ O & $w t \% N$ & wt\% C & wt\% $\mathrm{H}$ \\
\hline Ti-6Al-4V & 5.4 & 3.9 & - & $<0.18$ & $<0.03$ & $<0.05$ & $<0.015$ \\
\hline Ti-8Al-1Er (E-beam deposited) & 6.7 & - & 0.8 & 0.140 & 0.005 & 0.012 & 0.0008 \\
\hline Ti-8Al-1Er (Laser deposited) & 6.7 & - & 0.6 & \multicolumn{4}{|c|}{ Not measured } \\
\hline
\end{tabular}

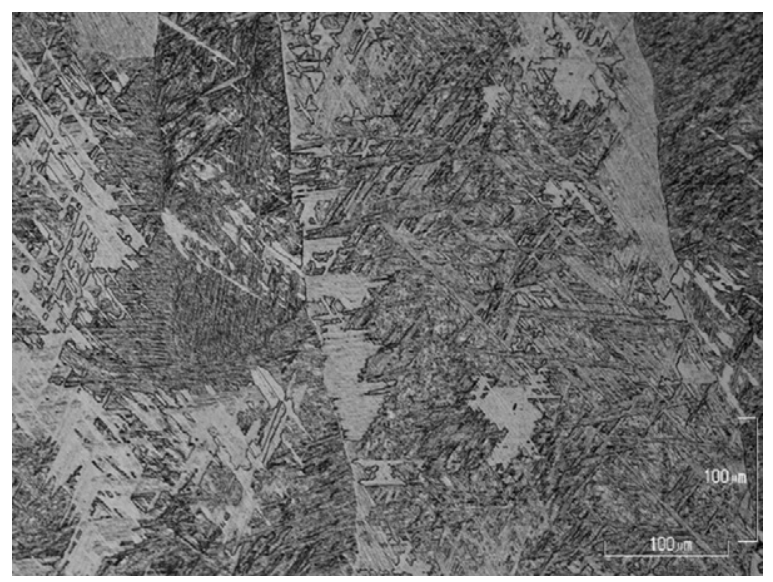

Fig. 4. Microstructure of electron beam deposited Ti-6Al-4V showing acicular structure.

beam deposited $\mathrm{Ti}-6 \mathrm{Al}-4 \mathrm{~V}$. However, based on the observations that the interstitial compositions of feedstock and test specimens of Ti-8Al-1Er were the same, the interstitial composition values in Table 1 reflect the specifications in AMS 4954 for the weld wire used in the fabrication process. Interstitial content of the laser deposited Ti-8Al-1Er from [16] was not measured. Data from another reference studying laser deposited $\mathrm{Ti}-8 \mathrm{Al}-1 \mathrm{Er}$ from the same time period indicated $\mathrm{O}, \mathrm{C}$, and $\mathrm{N}$ contents of $0.25,0.05$, and $0.15 \mathrm{wt} \%$ respectively [15]. The mechanical testing and characterization performed is summarized in Table 2.

\subsection{Elevated temperature tensile testing}

Since this study was an exploratory testing survey, only a single specimen was tested at each temperature. Each specimen was held at temperature for 10-15 min before beginning the test.

Heat was applied to the specimen through the use of two sets of quartz lamp heaters placed approximately $9.5 \mathrm{~mm}$ on either side of the specimen. Each heater contained four lamps individually controlled by its own temperature controller. Four thermocouples were spot welded to each specimen to act as feedback for the controllers. The width of each quartz lamp fixture was approximately $51 \mathrm{~mm}$. Therefore, the center $25 \mathrm{~mm}$ of the gage length was the only portion of the specimen held at the specified test temperature. A $12.7 \mathrm{~mm}$ gage length elevated temperature extensometer

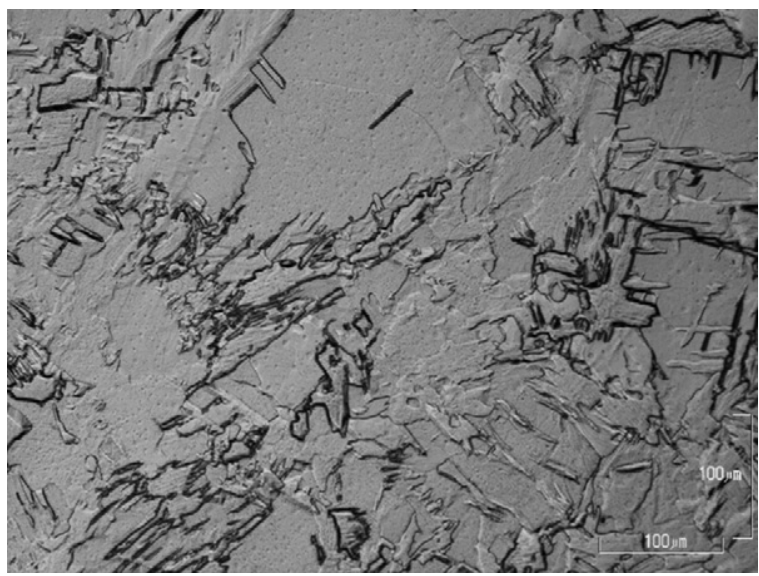

Fig. 5. Microstructure of electron beam deposited Ti-8Al-1Er.

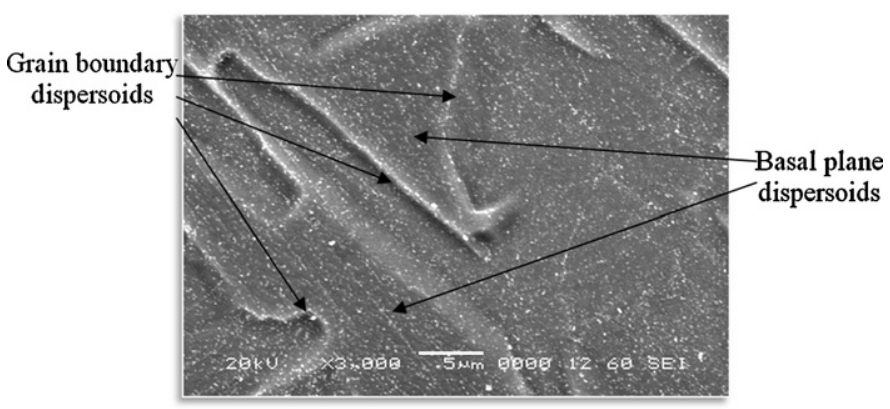

Fig. 6. SEM image of Ti-8Al-1Er microstructure. Note parallel strings of $\mathrm{Er}_{2} \mathrm{O}_{3}$ dispersoids indicative of formation along basal planes and dispersoids along grain boundaries.

with ceramic rods was used to measure strain. All tests were run in stroke control at a rate of $0.0254 \mathrm{~mm} / \mathrm{s}$.

\subsection{Creep testing}

Thirteen creep tests were performed, seven for Ti-8Al-1Er material and six for Ti-6Al-4V. The test matrix was designed to characterize both the stress and temperature dependence for each material. Tests were performed at a constant stress of $483 \mathrm{MPa}$ at temperatures of 425,445 , and $455^{\circ} \mathrm{C}$ in order to determine the activation energies and Larson-Miller parameters. Additional tests were performed at a single temperature $\left(445^{\circ} \mathrm{C}\right)$ over a stress range

Table 2

Mechanical testing and characterization summary.

\begin{tabular}{|c|c|c|c|c|}
\hline Test & Temperatures $\left({ }^{\circ} \mathrm{C}\right)$ & Output & $\begin{array}{l}\text { ASTM } \\
\text { standards used }\end{array}$ & $\begin{array}{l}\text { Number of } \\
\text { samples }\end{array}$ \\
\hline Tensile & 23 & $\begin{array}{l}\text { Yield strength, ultimate tensile strength, } \\
\text { elongation }\end{array}$ & E8 & 4 \\
\hline Elevated temperature tensile & $93,204,260,427,538$ & Yield strength, tensile strength, reduction of area & E21 & 12 \\
\hline Creep & $425,445,455$ & $\begin{array}{l}\text { Larson-Miller parameters, creep activation energy, } \\
\text { power law creep exponents }\end{array}$ & E139 & 13 \\
\hline Post-creep tensile & 23 & Yield strength, tensile strength, reduction of area & E8 & 8 \\
\hline Oxidation resistance & $600,700,800$ & Activation energy, parabolic rate constant & & 18 \\
\hline
\end{tabular}


Table 3

Room temperature tensile property comparison.

\begin{tabular}{|c|c|c|c|c|c|}
\hline & Ti-6Al-4V (E-beam) & Ti-8Al-1Er (E-beam) & Ti-8Al-1Er (Laser) [16] & $\begin{array}{l}\text { Ti-6Al-4V (Mill } \\
\text { anneal) }[22,23]\end{array}$ & $\begin{array}{l}\text { Ti-6Al-4V }(\beta \\
\text { anneal) }[22,23]\end{array}$ \\
\hline Yield strength (MPa) & 859 & 777 & Failed prior to yield & $830-924$ & $770-910$ \\
\hline UTS (MPa) & 907 & 832 & 970 & $900-993$ & $860-990$ \\
\hline Elongation (\%) & Not recorded & 19 & 0.1 & $10-15$ & 11 \\
\hline
\end{tabular}

of 414-483 MPa in order to determine the stress dependence, characterized with a power law exponent. Twelve of the thirteen tests were conducted at a single constant stress. The thirteenth test was conducted with a Ti-8Al-1Er specimen using a method of step changes in stress at a single temperature $\left(445^{\circ} \mathrm{C}\right)$. In this test the initial stress was $483 \mathrm{MPa}$. The stress was decreased in steps of 34.5 MPa to $414 \mathrm{MPa}$ and subsequently increased back to $483 \mathrm{MPa}$ in reverse manner. The magnitude of creep strain during each step was between 0.5 and $1.0 \%$. This procedure was followed two times to test for history effects. All tests were stopped at creep strains between 6.5 and $10 \%$. Several of the specimens were then tension tested at room temperature to measure the post-creep tensile properties.

\subsection{Oxidation resistance}

The oxidation resistance kinetics were measured at temperatures of 600,700 , and $800^{\circ} \mathrm{C}$ using specimens approximately $10 \mathrm{~mm} \times 10 \mathrm{~mm} \times 5 \mathrm{~mm}$ in size. The specimens were wet ground with 320,400 , and 600 grit $\mathrm{SiC}$ paper to ensure a uniform surface. This was followed by ultrasonic cleaning in hot ethyl alcohol. Specimen dimensions and weights were measured prior to elevated temperature exposure. The specimens were held at temperature for $2,10,25,50$, and $100 \mathrm{~h}$ on ceramic plates in furnaces containing a lab air atmosphere. After removal from the furnace, the specimens were weighed. The difference between the initial and final weights was attributed to oxygen uptake. Three specimens per condition (temperature/time) were measured. The mass gained per unit exposed area was plotted as a function of time and fit to a parabolic diffusion model to determine the parabolic rate constants at each temperature. The parabolic rate constants were plotted versus $1 / T$. When multiplied by the universal gas constant, $R$, the slopes of these latter curves yielded the oxidation activation energies [20,21].

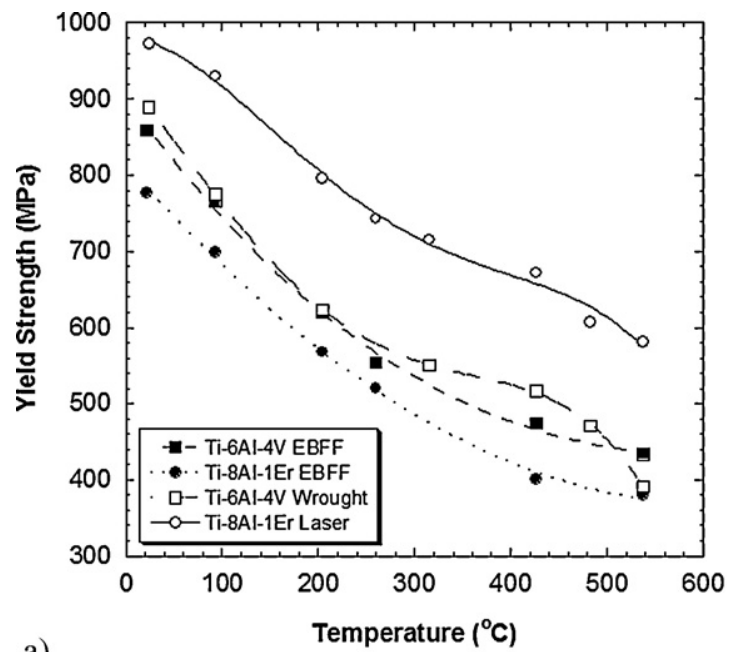

\section{Results}

\subsection{Room temperature tensile results}

Room temperature tensile test results are shown in Table 3 along with comparable data found in the literature from conventional sources. The Ti-8Al-1Er properties are also compared to a laser beam deposited product from a previous study [16].

Strength properties for the $\mathrm{Ti}-6 \mathrm{Al}-4 \mathrm{~V}$ product are within the published range. The static strengths of the Ti-8Al-1Er product are significantly lower than for the laser deposited product from the previous study. The bead deposit size for the laser deposited product was significantly less than that for the electron beam deposited product. This likely led to a much faster cooling rate. This is supported by the observed acicular microstructure observed in the case of the laser deposited product versus the equiaxed, annealed microstructure observed in the electron beam deposited product. It is also possible that increased interstitial content in the laser deposited material is a significant contributor to the observed strength differences. The strength differences between the electron beam and laser beam deposited material are consistent with reasonably expected differences in interstitial content.

\subsection{Elevated temperature tensile results}

Elevated temperature tensile results are shown in Figs. 7-9. Comparison is made to wrought Ti-6Al-4V (handbook and supplier data) and laser deposited Ti-8Al-1Er. Fig. 7 shows yield and ultimate tensile strength as a function of temperature. The electron beam additive manufactured and wrought forms of Ti-6Al-4V exhibit comparable response over the entire temperature range tested. The strengths of electron beam deposited $\mathrm{Ti}-8 \mathrm{Al}-1 \mathrm{Er}$ are 40-80 MPa less than those of the Ti-6Al-4V and 150-200 MPa less than laser deposited Ti-8Al-1Er. This is likely due to the significant difference in microstructure, thermal history and possible

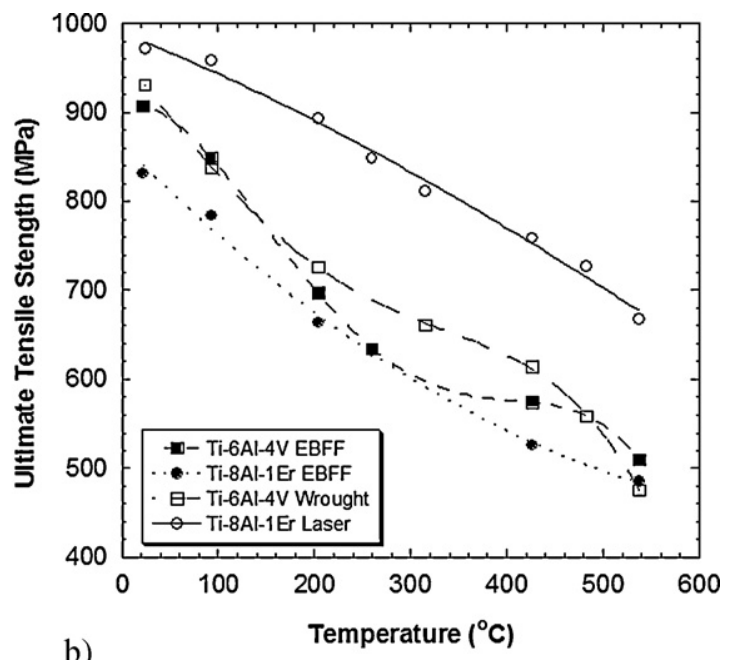

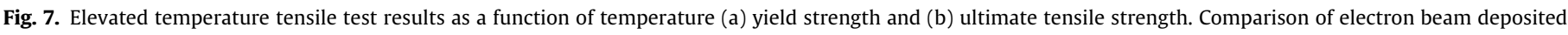
properties to wrought and laser deposited. 

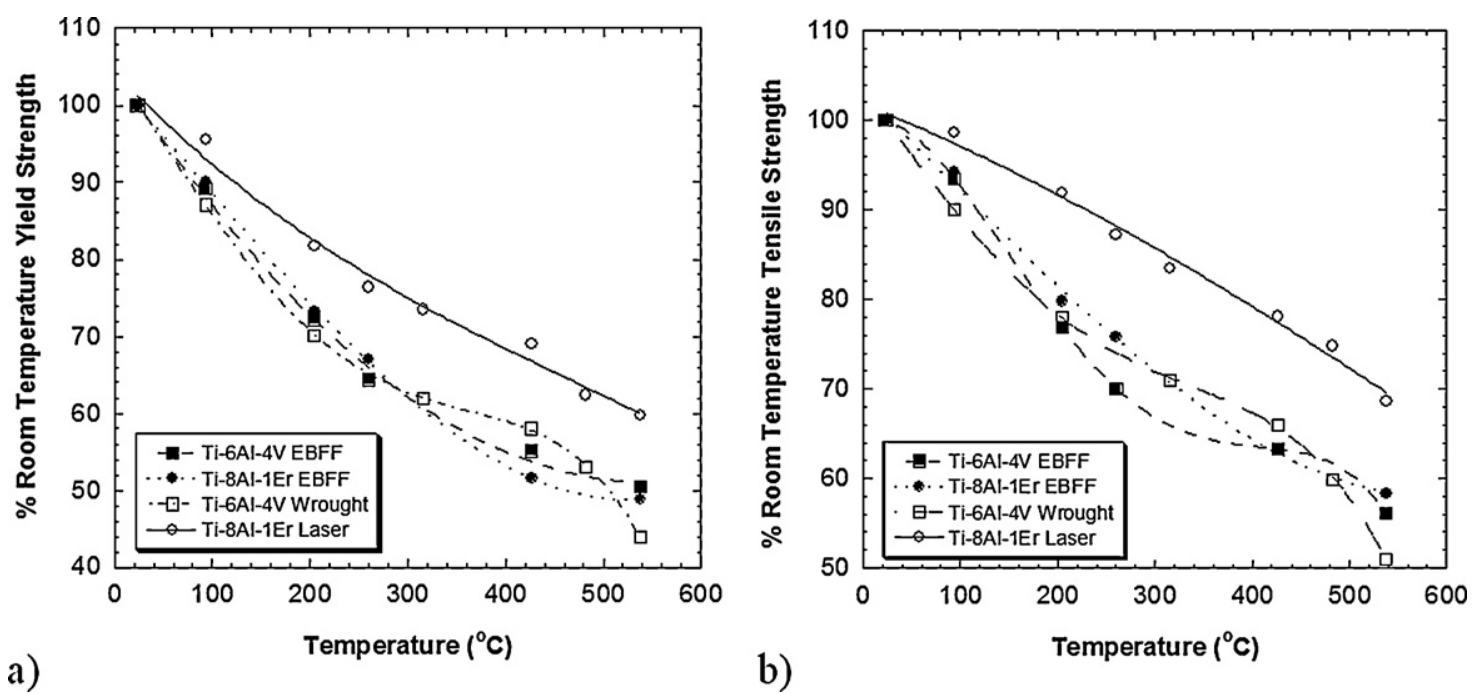

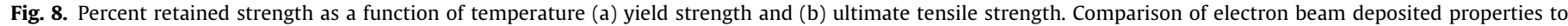
wrought and laser deposited.

interstitial content between the laser deposited and electron beam additive manufactured products.

Fig. 8 shows the results in terms of percentage of room temperature strength. In this case, both alloys exhibit a similar response to increasing temperature and losing strength at the same rate. The laser deposited material shows superior response and losing strength at a lower rate.

The ductility results in Fig. 9 are shown in terms of reduction of area rather than elongation. Standard elongation data assumes a gage length of $50.8 \mathrm{~mm}$. Since the gage lengths of the specimens used in this study were on the order of $13 \mathrm{~mm}$, comparison of elongation results with handbook data is inappropriate. It is observed that the Ti-6Al-4V material exhibits $10-30 \%$ greater reduction of area than the Ti-8Al-1Er material. Overall, both materials show adequate ductility.

\subsection{Creep results}

Creep testing was conducted prior to elevated temperature tensile testing. Creep test parameters were chosen based on results

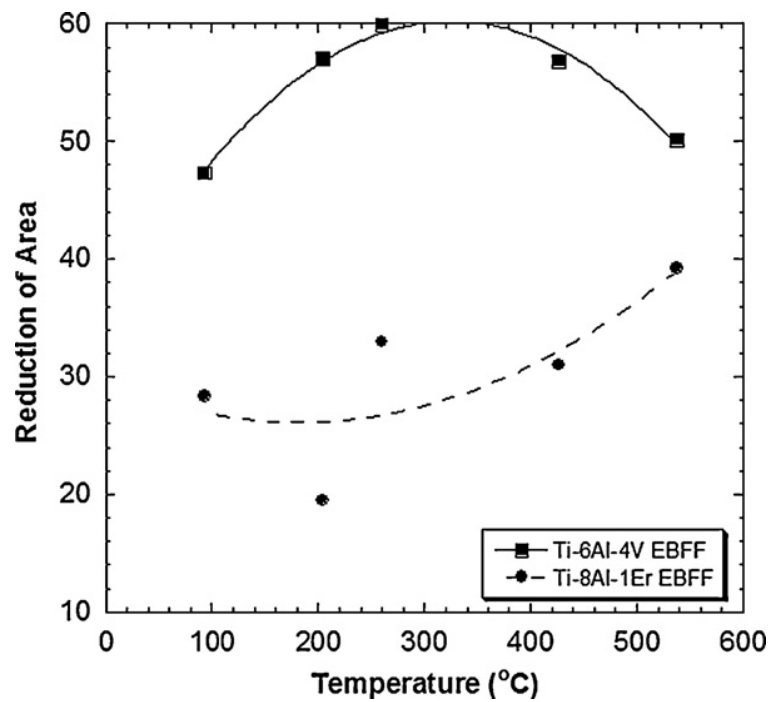

Fig. 9. Reduction of area as a function of temperature. Comparison of electron beam deposited products.

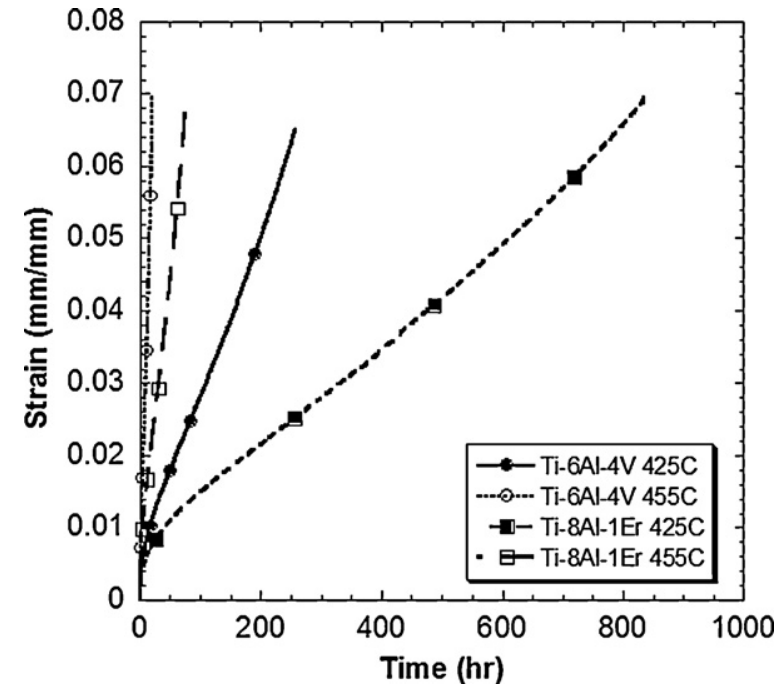

Fig. 10. Creep strain-time curves as a function of temperature (stress: $483 \mathrm{MPa}$ ).

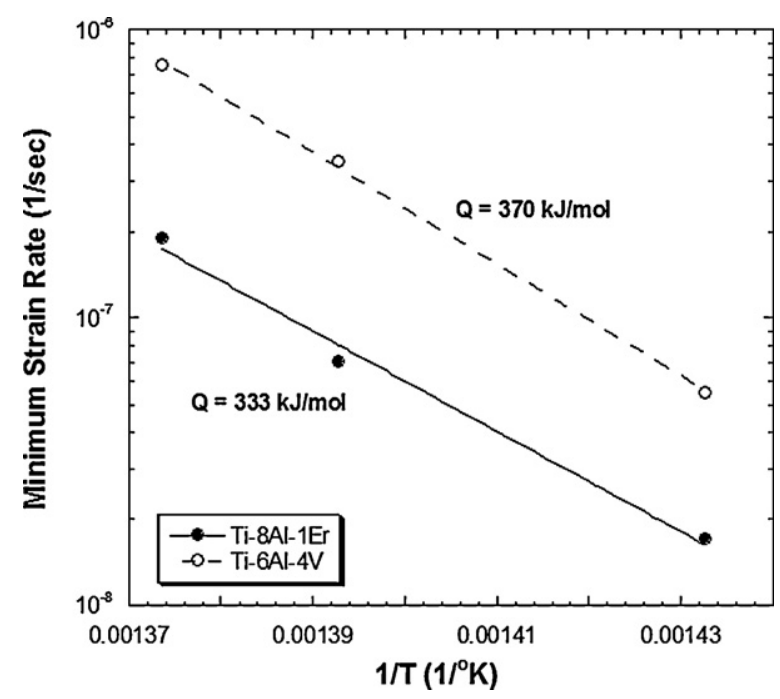

Fig. 11. Determination of creep activation energy at $483 \mathrm{MPa}$. 


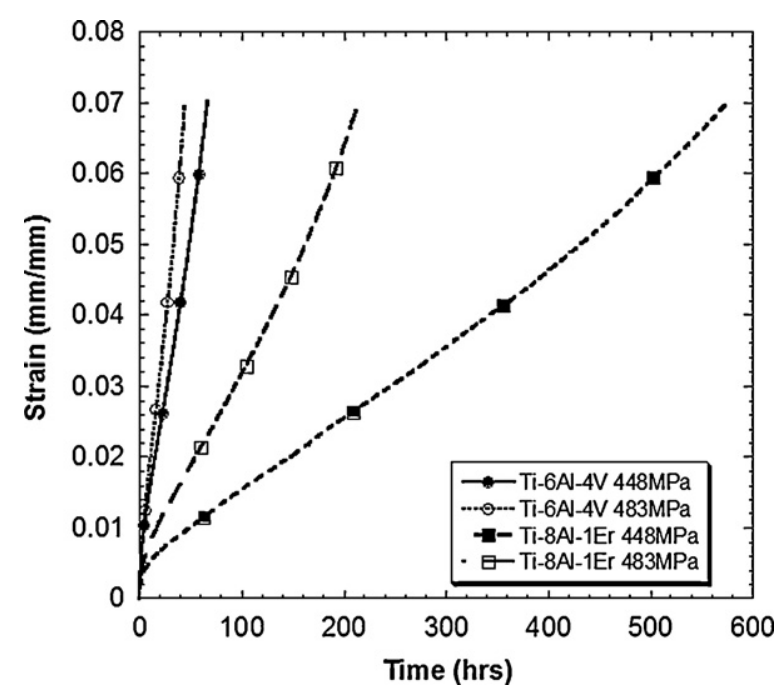

Fig. 12. Creep strain-time curves as a function of stress (temperature: $445^{\circ} \mathrm{C}$ ).

from previously tested laser deposited Ti-8Al-1Er [16]. Due to the lower-than-anticipated strength of the electron beam deposited erbium containing alloy, all creep tests for this alloy were conducted at stresses near or above its elevated temperature yield stress.

Sample creep strain versus time curves, as a function of temperature and at a constant stress of $483 \mathrm{MPa}$, are shown in Fig. 10. An increase in temperature from 425 to $455^{\circ} \mathrm{C}$ decreases the time to a given creep strain by a factor of $11-13$. The time required to achieve a given creep strain is 3-4 times greater for Ti-8Al-1Er than for Ti-6Al-4V. Plotting the minimum creep displacement rate for each curve, as a function of $1 / T$, Fig. 11, allows calculation of the activation energy for both alloys. The activation energies are 370 and $333 \mathrm{~kJ} / \mathrm{mol}$ for Ti-6Al-4V and Ti-8Al-1Er respectively. A statistical analysis of the uncertainty in the activation energies yielded values between 10 and $20 \%$ of the activation energies themselves. Thus, the difference between 370 and $333 \mathrm{~kJ} / \mathrm{mol}$ is statistically insignificant. Work by Koppers shows that the activation energy for self-diffusion in high purity $\alpha$-Ti is $303 \mathrm{~kJ} / \mathrm{mol}$ [24], which is on the order of that determined in this work. This would indicate dislocation climb as the primary creep mechanism.

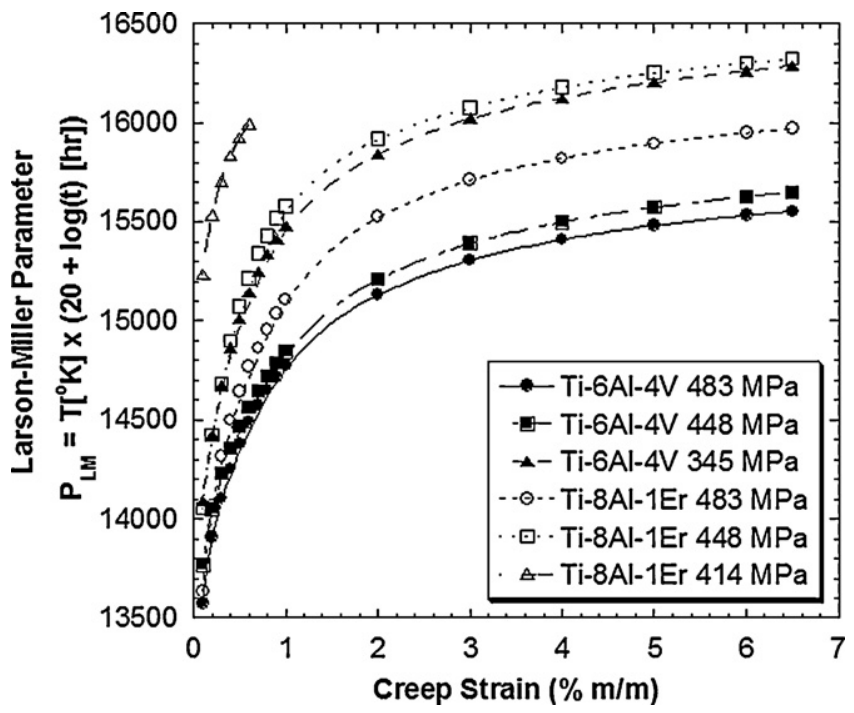

Fig. 13. Larson-Miller parameters $\left(P_{\mathrm{LM}}\right)$ as a function of creep strain, stress, and alloy.

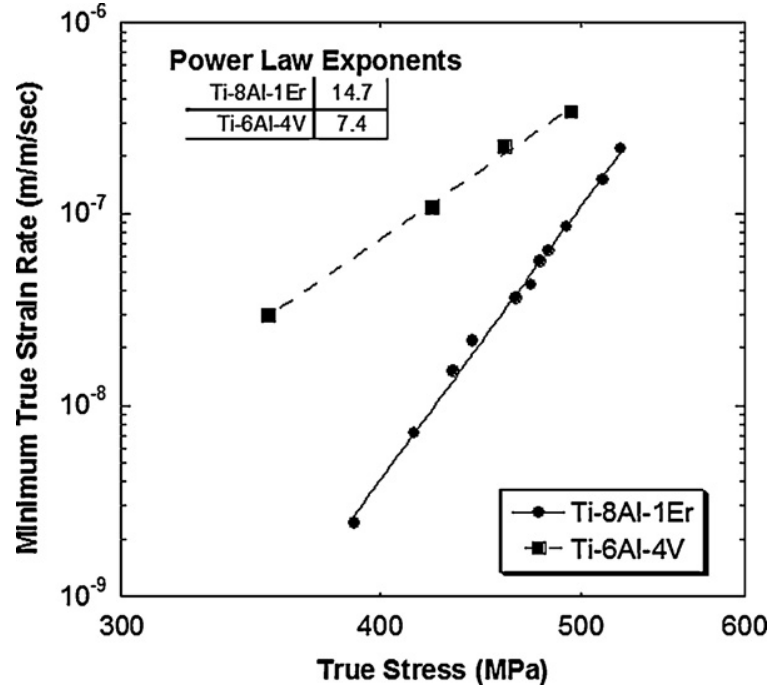

Fig. 14. Arrhenius plot used to determine power law exponents.

Sample creep strain versus time curves, as a function of stress and at a constant temperature of $445^{\circ} \mathrm{C}$, are shown in Fig. 12 . These curves show that $\mathrm{Ti}-8 \mathrm{Al}-1 \mathrm{Er}$ exhibits a greater sensitivity to applied stress than Ti-6Al-4V. A decrease in stress from 483 to $448 \mathrm{MPa}$, results in an increase in time to a given strain by factors of 1.5 and 2.7 for $\mathrm{Ti}-6 \mathrm{Al}-4 \mathrm{~V}$ and $\mathrm{Ti}-8 \mathrm{Al}-1 \mathrm{Er}$ respectively. Note that at the lower stress of $448 \mathrm{MPa}$, the time to a given creep strain is at least 10 times greater for the erbium containing alloy than Ti-6Al-4V.

Larson-Miller parameters (time-temperature parameters used to predict extended-time creep lives from short-time tests) are shown in Fig. 13. As expected, the plot indicates that the Larson-Miller parameter increases with increasing creep strain and decreasing stress. The data also implies a greater stress sensitivity for the Ti-8Al-1Er alloy than the Ti-6Al-4V. At lower stresses, the creep life of the erbium containing alloy increases much faster than for Ti-6Al-4V.

Fig. 14 shows the relationship between minimum true creep strain rates and true stress at $445^{\circ} \mathrm{C}$. This data can be used to compute power law creep exponents, assuming that the creep strain rate is proportional to $\sigma^{m}$, where $\sigma$ is the true creep stress and $m$ is the power law exponent. Typical power law exponents for metals range from 3 to 8. Exponents for dispersion strengthened metals are often greater than 10 [38-41]. The behavior of the two alloys tested is consistent with these observations, as the exponents are 7.4 and 14.7 for Ti-6Al-4V and Ti-8Al-1Er respectively.

Creep stability, as measured by the change in tensile properties between as-received and post-creep tested material, is shown in Table 4. For both alloys, the yield strength increases by an average of $150 \mathrm{MPa}$, the ultimate tensile strength increases by an average of $110 \mathrm{MPa}$, and the reduction of area decreases by about $20 \%$. The results are independent of time at temperature and weakly dependent on applied stress. These trends are consistent with data for Ti-6Al-4V in Boyer [25], which shows that tensile strength increases and ductility decreases during the long-term elevated temperature exposures and stresses imposed during creep testing. The magnitudes of the yield strength and reduction of area changes in this study are greater than those reported by Boyer.

\subsection{Fractography}

Fractography of tested tensile specimens revealed fracture surfaces characterized by dimpled rupture in both alloys. Sample fracture surfaces are shown in Fig. 15. 
Table 4

Tensile properties prior to and post-creep exposure.

\begin{tabular}{|c|c|c|c|c|}
\hline & \multicolumn{2}{|c|}{ Ti-6Al-4V (E-beam deposited) } & \multicolumn{2}{|c|}{ Ti-8Al-1Er (E-beam deposited) } \\
\hline & As-received & Post-creep & As-received & Post-creep \\
\hline Yield strength (MPa) & 859 & $\begin{array}{l}\text { 971-1023 } \\
\text { Mean - } 995\end{array}$ & 777 & $\begin{array}{l}895-980 \\
\text { Mean - } 934\end{array}$ \\
\hline UTS (MPa) & 907 & 991-1037Mean - 1018 & 832 & 991-997Mean - 949 \\
\hline Reduction of area (\%) & 47 & 28 & 28 & 10 \\
\hline
\end{tabular}

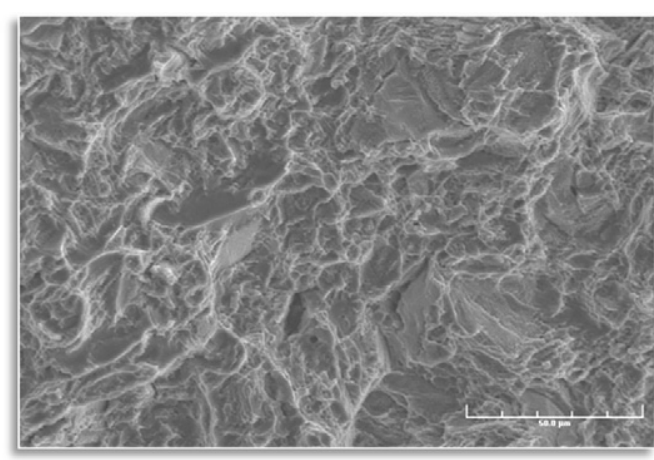

a)

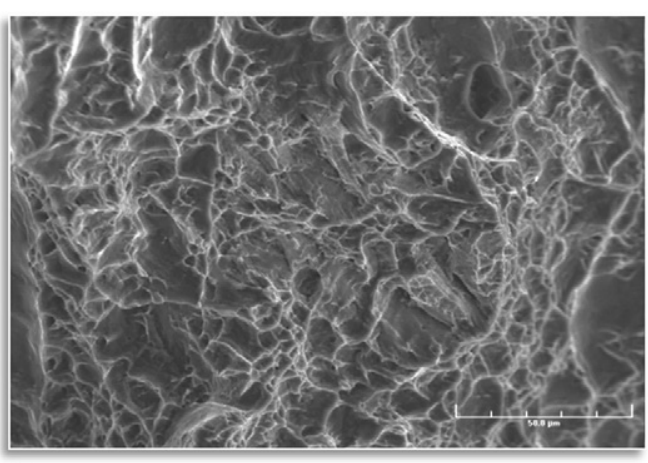

b)

Fig. 15. Typical fracture surfaces of tested tensile specimens. (a) Ti-8Al-1Er and (b) Ti-6Al-4V both alloys exhibit ductile, dimpled fracture features.
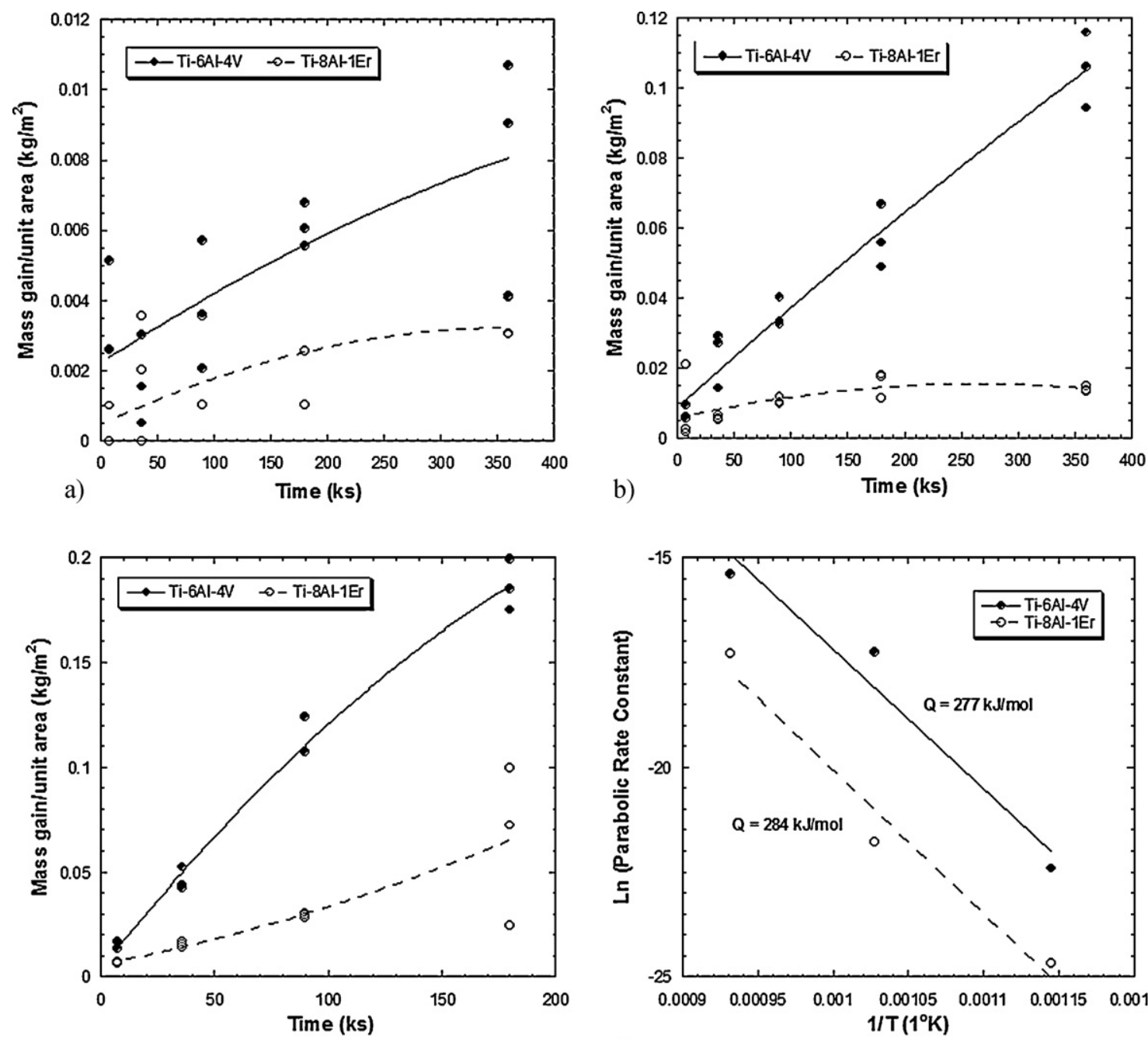

c)

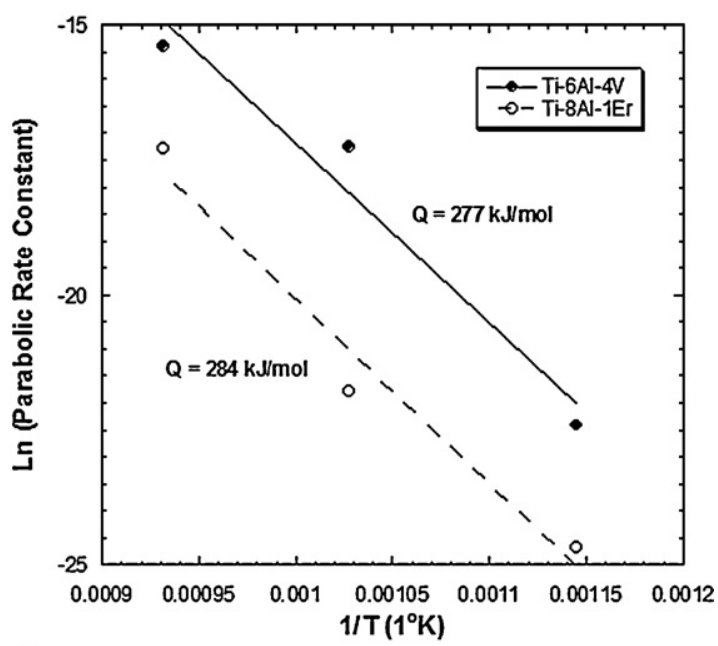

d)

Fig. 16. Mass gain/unit area as a function of time (a) $600^{\circ} \mathrm{C}$, (b) $700^{\circ} \mathrm{C}$, (c) $800^{\circ} \mathrm{C}$, and (d) oxidation activation energy determination. 


\subsection{Oxidation resistance}

Weight gain versus time plots at temperatures of 600,700 , and $800^{\circ} \mathrm{C}$ for both alloys are presented in Figs. 16 (a-c). Parabolic curve fit trend lines for each data set are also shown. The linear coefficients of the trend line fits for weight gain squared versus time at temperature were then used to compute apparent activation energies. The Arrhenius plot for apparent activation energy determination is shown in Fig. 16d. This shows activation energies of 277 and $284 \mathrm{~kJ} / \mathrm{mol}$ for Ti-6Al-4V and Ti-8Al-1Er respectively. The differences in these values are not statistically significant.

These results show that the oxidation kinetics for Ti-8Al-1Er are significantly less than for Ti-6Al-4V. However, the activation energies indicate that the same mechanism is operating in both alloys. Oxidation activation energies reported in the literature for Ti-6Al-4V and $\alpha$-titanium with and without dispersoids range from 60 to $300 \mathrm{~kJ} / \mathrm{mol}$ [20,21,26-29]. The activation energies reported in this study are in the upper region of this range.

\section{Discussion}

Commercial elevated temperature titanium alloy development is a complex process that balances chemical composition, heat treatment, and processing to obtain microstructures with a given set of properties that include elevated temperature tensile, creep, oxidation resistance, fatigue and fatigue crack growth resistance and fracture toughness [30-33]. Only a subset of these properties are addressed in this study. In addition, no attempt was made in this study to optimize alloy chemistry, electron beam deposition parameters, or heat treatment.

The primary goal was to determine if the electron beam additive manufactured process would result in titanium material with acceptable mechanical properties. In the case of Ti-6Al-4V, acceptable properties are those of the traditional ingot based wrought material. All the properties generated in this study for this product are comparable to those published for wrought $\mathrm{Ti}-6 \mathrm{Al}-4 \mathrm{~V}$, thus indicating that the electron beam additive manufacturing method could be an acceptable fabrication route for Ti-6Al-4V parts. However, more work must be done to ensure that the process produces parts with reproducible and consistent properties.

For the Ti-8Al-1Er alloy composition, the goals are significantly different. Much of the previous work done on rare-earth containing titanium alloys have used rapid solidification process routes, such as gas atomization or splat quenching, in order to obtain the fine dispersion sizes necessary for these alloys to be effective. One of the problems encountered in this work was avoiding excessive dispersoid particle coarsening that often occurs during the consolidation and forging operations necessary for creating functional parts out of the rapidly solidified material. The primary goal of this study is to determine how effectively an electron beam additive manufacturing process could produce a fully-dense product with the fine dispersoids necessary for high temperature performance. This study also aimed to compare property improvement trends noted in previous work on rapidly solidified rare-earth containing titanium alloys to the properties of a product made by electron beam deposition. Since the electron beam deposition process fabricates net or near-net shape parts, no thermomechanical post-processing is required, thus avoiding any detrimental microstructure changes.

Previous work on rare-earth dispersoid containing titanium alloys showed that creep resistance, strength, fatigue resistance, and oxidation resistance are improved [11-14,34-37]. Proposed mechanisms for the improvements include microstructural control due to dispersoid presence and dislocation pinning. The results of this study and that in [16] dealing with laser-deposited material support the previous work. The properties measured in [16] most closely approximate those measured in previous work that utilized rapid solidification fabrication techniques. In particular, the room temperature and elevated temperature tensile properties and creep resistance of the laser deposited product were greater than those of the electron beam deposited product. This indicates that differences in thermal processing history and microstructure between material fabricated in laser and electron beam deposition processes are significant. Of particular importance is the relative size of the molten pool in the two processes and the effect this has on the solidification rate and the resulting dispersoid distribution. Process parameter-microstructure-property interactions should be studied to optimize the property sets of interest. It should also be noted that differences in interstitial content could be a significant contributor to the strength differences.

A secondary goal is to compare properties of the electron beam additive manufactured $\mathrm{Ti}-8 \mathrm{Al}-1 \mathrm{Er}$ to those of widely used commercial alloys. Results show that the creep and oxidation resistances of electron beam additive manufactured $\mathrm{Ti}-8 \mathrm{Al}-1 \mathrm{Er}$ are superior to that of $\mathrm{Ti}-6 \mathrm{Al}-4 \mathrm{~V}$, but that the tensile properties are slightly lower. The work on laser-deposited Ti-8Al-1Er suggests that control of process parameters may be able to address this issue. Although, not specifically addressed in this paper, it is worth noting that the elevated temperature properties of both laser-deposited and electron beam deposited rare-earth modified titanium alloys are no better than existing high-temperature titanium alloys, such as Ti-6242S or IMI834. However, optimization of the rare-earth alloy composition and the operating parameters of electron beam additive manufacturing processes could produce material with exceptional properties exceeding those of established conventional alloys. The use of rare-earth modified titanium alloys may provide an alternate route to high temperature performance or provide a means to enhance alloys already in existence. Electron beam additive manufacturing provides a possible alternative to rapid solidification methods to utilize this rare-earth modified technology.

\section{Summary}

Based on the test data generated in this study the following conclusions are justified:

(a) Elevated temperature properties of electron beam deposited Ti-6Al-4V are comparable to those of the wrought form. Thus, electron beam additive manufacturing could be a viable fabrication process for titanium parts.

(b) Elevated and room tensile temperature properties of electron beam formed, dispersion strengthened $\mathrm{Ti}-8 \mathrm{Al}-1 \mathrm{Er}$ are comparable to electron beam formed $\mathrm{Ti}-6 \mathrm{Al}-4 \mathrm{~V}$ and inferior to a previous lot of laser beam deposited material.

(c) Creep and oxidation resistances of the dispersion strengthened alloy are significantly better than a conventional $\alpha-\beta$ alloy.

(d) The electron beam deposition process enables successful fabrication of rare-earth dispersion strengthened titanium alloys. This opens up a fabrication route that can be used to create new elevated temperature resistant titanium alloys or a method to improve alloys already in existence.

\section{Acknowledgments}

The work of Deb Sweeney, C1C Tyler Haunreiter, C1C Benjamin Keisler, and C1C Jonathan Lewis in generating the oxidation resistance data at the US Air Force Academy and the work of Susanne Waltz of NASA-Langley for graphics preparation is gratefully acknowledged by the authors. 


\section{References}

[1] K. Taminger, Adv. Mater. Processes 165 (11-12) (2009) 45.

[2] C.A. Brice, K.M. Taminger, R.A. Hafley, Adv. Mater. Processes 163 (4) (2005) 32

[3] R.A. Hafley, K.M. Taminger, R.K. Bird, Collection of Technical Papers - 45th AIAA Aerospace Sciences Meeting 20 (2007) 13879-13887.

[4] V.R. Dave, J.E. Matz, T.W. Eager, Proceedings of 6th SFF Symposium, 1995, pp. 64-71.

[5] K.M. Taminger, R.A. Hafley, M.S. Domack, Mater. Sci. Forum 519-521 (Part 2) (2006) 1297-1304.

[6] M.S. Domack, K.M. Taminger, M. Begley, Mater. Sci. Forum 519-521 (Part 2) (2006) 1291-1296.

[7] J.E. Matz, TW. Eager, Metall. Mater. Trans. A 33 (8) (2002) 2559-2567.

[8] U. Ackelid, M. Svensson, Mater. Sci. Technol. Conf. Exhib. 20094 (2009) 2711-2719.

[9] D. Cormier, O. Harrysson, H. West, Rapid Prototyping J. 10 (1) (2004) 35-41.

[10] P. Wanjara, M. Brochu, M. Jahazi, Mater. Sci. Forum 539-543 (Part 5) (2007) 4938-4943.

[11] S.M.L. Sastry, P.J. Meschter, J.E. O’Neal, Metall. Trans. A 15A (7) (1984) 1451-1463.

[12] S.M.L. Sastry, S.C. Peng, L.P. Beckerman, Metall. Trans. A 15A (7) (1984) 1465-1474.

[13] R.G. Rowe, E.F. Koch, in: P.W. Lee, R.S. Carbonara (Eds.), Rapidly Solidified Materials, American Society for Metals, Metals Park, OH, 1985, pp. 115-120.

[14] C.S. Chi, S.H. Whang, Mechanical behavior of rapidly solidified materials, in: S.M.L. Sastry, B.A. McDonald (Eds.), The Metallurgical Society of AIME, 1985, pp. 231-245.

[15] C.A. Brice, H.L. Fraser, J. Mater. Sci. 38 (7) (2003) 1517-1521.

[16] R. Bush, C. Brice, J. Baer, T. Skaar, Proc. TMS Fall Meeting (2002) 149-163.

[17] C.A. Brice, MS Thesis, The Ohio State University, 2000.

[18] D.G. Konitzer, J.T. Stanley, M.H. Loretto, H.L. Fraser, Acta Metall. 34 (7) (1986) $1269-1277$.

[19] C.A. Brice, B.T. Rosenberger, S.N. Sankaran, K.M. Taminger, B. Woods, R. Nasserrafi, Mater. Sci. Forum 618-619 (2009) 155-158.

[20] M.N. Mungole, N. Singh, G.N. Mathur, Mater. Sci. Technol. 18 (1) (2002) $111-114$.
[21] S. Frangini, A. Mignone, F. de Riccardis, J. Mater. Sci. 29 (1994) 714-720.

[22] R. Boyer, G. Welsch, E.W. Collings, Materials Properties Handbook: Titanium Alloys, 524-526, ASM International, Materials Park, OH, 1994, p 608.

[23] M.J. Donachie, Titanium: A Technical Guide, ASM International, Materials Park, OH, 1988, p. 172.

[24] M. Koppers, C.H.R. Herzog, M. Friesel, Y. Mishin, Acta Mater. 45 (1997) 4181-4191.

[25] R. Boyer, G. Welsch, E.W. Collings, Acta Mater. (1994) 532, London, England.

[26] Y. Qin, D. Zhang, W. Lu, W. Pan, J. Alloys Compd. 455 (1-2) (2008) 369-375.

[27] E. Zhang, G. Zeng, S. Zeng, J. Mater. Sci. 37 (19) (2002) 4063-4071.

[28] H. Guleryuz, H. Cimenoglu, J. Alloys Compd. 472 (1-2) (2009) 241-246.

[29] J. Unnam, R.N. Shenoy, R.K. Clark, Oxid. Met. 26 (3-4) (1986) 231-252.

[30] P.A. Blenkinsop, Materials in Aerospace: The First International Conference, Royal Aeronautical Society, London, England, 1986, pp. 189-208.

[31] P.A. Blenkinsop, D.F. Neal, Proc. 1 Int. Symp. Metall. Technol. Pract. Titanium Alloys, Minerals, Metals, and Materials Society (TMS), Warrensburg, PA, 1994, pp. 19-27.

[32] P.J. Bania, ISIJ Int. 31 (8) (1991) 840-847.

[33] D. Eylon, S. Fujishiro, F.H. Froes, High Temp. Mater. Processes (Lond.) 6 (1-2) (1984) 81-91.

[34] M.F.X. Gigliotti, G.E. Wasielewski, R.G. Rowe, Conf. Proc.: Titanium: Rapid Solidification Technology, Metallurgical Society of AIME, 1986, pp. 141-151.

[35] M.F.X. Gigliotti, R.G. Rowe, G.E. Wasielewski, G.K. Scarr, J.C. Williams, Mater. Res. Soc. 58 (1986) 343-351.

[36] R.G. Vogt, D. Eylon, F.H. Froes, Conf. Proc. Titanium: Rapid Solidification Technology, Metallurgical Society of AIME, 1986, pp. 177-194.

[37] C. Suryanarayana, F.H. Froes, R.G. Rowe, Int. Mater. Rev. 36 (3) (1991) 85-123.

[38] N.E. Dowling, Mechanical Behavior of Materials, 3rd edition, Pearson Prentice Hall, 2007, p. 784.

[39] G. Gonzalez-Doncel, O.D. Sherby, Acta Metall. Mater. 41 (10)(1993)2797-2805.

[40] H. Hofmann, G. Frommeyer, C. Derder, Mater. Sci. Eng. A 245 (1998) 127-134.

[41] L.M. Peng, S.J. Zhu, F.G. Wang, H.R. Chen, Z.Y. Ma, J. Bi, J. Mater. Sci. 33 (1998) 5643-5652. 